\title{
Internationalising teacher education for a "glocal" curriculum: South Koreans learning to teach Hong Kong Liberal Studies
}

\author{
Liz Jackson (corresponding author)
}

Faculty of Education, University of Hong Kong, Hong Kong

\section{lizj@hku.hk}

Liz Jackson is an Assistant Professor in the Division of Policy, Administration, and Social Sciences Education and Deputy Director of the Master of Education Programme for the Faculty of Education at the University of Hong Kong. Her book, Muslims and Islam: Reconsidering Multiculturalism (Routledge, 2014) won the Philosophy of Education Society Book Award for 2015 as well as the University of Hong Kong Research Output Prize (Education, 2015). Jackson is Principal Investigator for the research project "Representation of ethnic and religious minorities in school textbooks: Aligning multiculturalism and Liberal Studies,” funded by the Research Grants Committee of the University Grants Committee of Hong Kong.

\section{Ana Yoon Jin Han \\ Christian Alliance P.C. Lau Memorial International School, Hong Kong haanyoonjin@gmail.com}

Ana Yoon Jin Han is an English and Social Studies Secondary Teacher at Christian Alliance P.C. Lau Memorial International School, Hong Kong. She graduated from the University of Hong Kong Liberal Studies Teacher Education Programme in 2015. From 2013-2015 she was a Student Research Assistant for the project led by Liz Jackson (Principal Investigator), "Representation of ethnic and religious minorities in school textbooks: Aligning multiculturalism and Liberal Studies,” funded by the Research Grants Committee of the University Grants Committee of Hong Kong.

This work was supported by the University Grants Committee Early Career Scheme Award and Education Plan under Grant [number 106130225]. 


\title{
Internationalising teacher education for a "glocal" curriculum: South Koreans learning to teach Hong Kong Liberal Studies
}

\author{
Internationalisation in education facilitates student and teacher mobility. Though Hong Kong \\ has embraced internationalisation in education, international university students can face \\ challenges related to cultural difference. In teacher education these challenges can be \\ amplified, as student teachers face expectations to teach schoolchildren within the local \\ cultural context. Past studies in Hong Kong have illustrated how Mainland Chinese student \\ teachers face cultural and linguistic obstacles. Yet little research considers the experiences of \\ student teachers from different nationalities in Hong Kong. This study investigates some \\ consequences of internationalisation of teacher education in Hong Kong by examining the \\ case of South Korean students learning to teach Liberal Studies, a "glocal” (outward-looking, \\ but localised) subject, in a major tertiary institution. In this paper we investigate South \\ Korean students' motivations, experiences, and challenges learning to be international \\ teachers of a glocal curriculum, and examine the case as one instance of globalisation of \\ education.
}

Keywords: Hong Kong, Liberal Studies, internationalisation, higher education, teacher education, international students

\section{Introduction}

Globalisation has infused various aspects of societies around the world, increasing movement of human and other resources across borders. Internationalisation in education, including teacher training, is a crucial facilitator of both student and teacher mobility. Hong Kong, known as “Asia’s World City”, has embraced internationalisation in education, with several of its universities rated among the most international according to global rankings. However, international university students can face challenges related to cultural difference in Hong Kong. Echoing international findings, such difficulties are likely to occur during adaptation to the host learning and teaching community (Altbach \& Knight, 2007; Ilieva, Beck \& Waterstone, 2014; Montgomery 2010). In undergraduate teacher education these challenges can be amplified, as student teachers also face expectations to engage effectively 
alongside local counterparts in teaching students with different cultural and linguistic backgrounds from their own (Gu, 2013).

Past studies have illustrated cultural and linguistic obstacles faced by Mainland Chinese student teachers, the largest non-local group of university students in Hong Kong (Gu, 2013; Gu \& Lai, 2012). However, there is little research elaborating the experiences of international student teachers in Hong Kong. Despite facing cultural differences, international teacher education students might be particularly able to support Hong Kong's commitment to internationalisation in education as they strive to become international teachers in the society. In particular, the recently introduced (2009) "Liberal Studies" curriculum, which aims to engage students in appreciating diversity in society (Jackson, 2014a; CDC, 2007/2014), represents a rich space for international student teachers and international teachers in Hong Kong to support internationalisation efforts that benefit students.

This study investigates some consequences of internationalisation in teacher education in Hong Kong, by closely examining the case of South Korean teacher education students learning to teach Liberal Studies in one tertiary institution. In this paper we investigate and reflect upon South Korean students' motivations, experiences, and challenges in learning and training to become international teachers of a "glocal” Hong Kong curriculum: that is, a locally framed and constructed curriculum, that has an outward-looking face. After reporting on our research, we explore some implications of this case for international teacher education more generally.

\section{Internationalisation in higher education and school teaching}

At the broadest level, internationalisation of higher education is fuelled by student desires for global-level knowledge and societal priorities for economic growth and market stabilisation in the age of globalisation (Rizvi \& Lingard, 2010; Stier, 2004). Students attend universities overseas to benefit from knowledge and perspectives from a different society. 
This is not a new phenomenon, but has been common among elites throughout the history of the university. On the other hand, universities have more recently been encouraged to play a part in international cooperation, to enhance their society's capacity to thrive in the capitalist global economy, which is another major factor in internationalisation efforts (Altbach \& Knight, 2007; Ilieva et al., 2014; Krucken \& Meier, 2006; Rizvi \& Lingard, 2010).

Idealism, instrumentalism, and educationalism are three perspectives (as labelled by Stier, 2004) providing distinct justifications for university-level internationalisation. Idealism is the belief that "internationalization is good per se" (Stier, 2004, p. 88, emphasis in original). Echoing traditional student sensibilities on internationalisation, this rationale stems from universal cosmopolitanism and the hope that human knowledge can enhance societal and global progress as it broadens awareness of global trends, diverse social issues, and interconnectedness (Jackson, 2016). Such idealism undergirds many broad claims regarding globalisation: enhanced mutual understanding across groups which arises through international interrelations can aid world peace and decrease the harms of racism, ethnocentrism, and large-scale so-called clashes of civilisations; diversity stemming from internationalisation makes organizations more creative, open, dynamic, and flexible; and so on (Burchill, 2009; Giddens, 1990; Wanner, 2015).

However, critics note that such globalist sentiments undergirding idealism can overlook tendencies in reality toward global convergence: “a one-way flow [of ideas], approached within the realms of the 'rich world's' value systems” (Stier, 2004; also Ritzer, 1993; Rizvi \& Lingard, 2010). Inequalities and differences in values across societies and communities linger on, as standardisation practices implicit in internationalisation lead to loss or neglect of indigenous knowledge (Ashcroft, Griffiths \& Tiffin, 1995), ignorance of the experiences of disadvantaged players in the global system, and a favouring of elite perspectives and values. Thus, idealism can have both democratising and homogenizing 
impacts on higher education, as universal cosmopolitanism can be seen as empowering or oppressive toward different communities worldwide.

Another ideological perspective shaping internationalisation of education is instrumentalism, which sees "higher education to be one means to maximise profit, ensure economic growth and sustainable development, or to transmit desirable ideologies of governments, transnational corporations, interest groups or supranational regimes” (Stier, 2004, p. 90). This framing foregrounds competition of higher education institutions and using internalisation to enhance global standing (Altbach \& Knight, 2007). Applying this view to the case of the European Union (EU), policymakers' urge to increase transparency of national educational systems can be seen as an attempt to standardise the credential acquisition process, to increase the mobility of the labour force internationally. At the individual student level, internationalisation can foster students’ flexibility and readiness to apply their skills in multicultural and international contexts, increasing their competitiveness in the global market. Education and knowledge are viewed as market goods according to the instrumentalist view, which finds support across university mission statements worldwide which emphasize the importance of attracting and recruiting diverse students and researchers globally (Scott, 2006).

In relation to instrumentalism, critics charge that such policies and ideology reflect an overly pragmatic, potentially cynical, view of education's value, reducing its use narrowly for competition in neoliberal contexts and neglecting its intrinsic, noneconomic value at global and local levels (Besley, 2012). It can lead to "brain drain,” as people migrate to study but may not return to contribute to their home countries, thus exacerbating global inequities. Furthermore, it is feared that knowledge and values not geared to global capitalist economic production and market integration in research, teaching, and learning may be dismissed from an instrumentalist standpoint, if neoliberal considerations are prioritized above all else (Rizvi \& Lingard, 2010). 
A third view, educationalism, regards internationalised education as valuable for students' academic enrichment, as it provides access to new and unfamiliar cultures, curricula, ideas, and norms, to both local and international students. Such exposure can challenge students, as engagements with the foreign are not always pleasant, and may trigger feelings of anxiety, uncertainty, and frustration. However such challenges are deemed fruitful for selfactualisation, reflection, and personal growth. In a sense, educationalism as part of internationalisation stems from multicultural educational initiatives of earlier eras, which underscored how understanding others and developing an open mind toward new perspectives and ideas is productive not just for enhancing equality and justice in society, but for enhancing mainstream students' capabilities to understand and interact with the world around them (Jackson, 2014a). Thus universities around the world increasingly have diversity curriculum requirements and encourage international service or experiential learning, inviting students in various ways to study languages, cultures, or history outside of national borders (Otten, 2003).

Yet while potentially beneficial to students, educationalism can be flawed in practice, as educational systems are in reality inevitably impacted by "academicentrism," a kind of educational ethnocentrism (Stier, 2004; see Altbach \& Knight, 2007). Educational policy makers and instructors' possible lack of comprehension of or appreciation for foreign curricula and pedagogies and international students' experiences and backgrounds may lead to their unwitting “conviction that 'our' methods of teaching, research and degrees are better than those of other countries” (Stier, 2004, p. 93). International students in this context may feel reject their own backgrounds and experiences, in nonalignment with other higher education priorities of student-centred learning and multicultural and intercultural education (Ashcroft, Griffiths \& Tiffin, 1995). 
As internationalisation in education increases, global mobility of schoolteachers is also rising. Most international schoolteachers teach English, regarded as a global communication tool in many countries (Crystal, 1997; Graddol, 1997). Particularly in the Asia Pacific region (in Hong Kong, South Korea, Japan, and Taiwan) governmental-run schemes recruit native English speakers to enhance the societies' language education (Wang \& Lin, 2013). Native-speaking English Teachers (NETs) are recruited in Hong Kong to develop and teach curricula in local schools for English as a second language (Forrester \& Lok, 2008). The other most popular domain for the employment of international educators worldwide is international (primary and secondary) schools, which may hire locally based foreigners (such as the spouses of expatriate workers) as valuable cultural bridges, or recruit internationally as feasible (Garton, 2000).

As is the case for students, it has been observed that feelings of culture shock and associated stress and anxiety can plague international schoolteachers (von Kirchenheim \& Richardson, 2005). In NET schemes in Japan, Hong Kong, South Korea, and Taiwan, challenges have been observed related to cooperation, communication, and cultural difficulties between NETs and local teachers (Carless \& Walker, 2006; Choi, 2001; Wang, 2013). In Korea, cultural differences of NETs and local teachers are cited as a crucial factor (Choi, 2001); in Hong Kong they often possess "little shared understanding or common philosophy” (Carless \& Walker, 2006, p. 465). Studies of international teachers working in the United Kingdom (McNamara, Lewis \& Howson, 2005), Australia (Reid, Collins \& Singh, 2014), and in developing countries through international volunteer programmes (Jackson \& Adarlo, 2016) find that such educators can face significant difficulties with cultural adaptation and discrimination and prejudice within schools and communities. However, the experiences of locally trained international teachers may differ substantially from that of migrant teachers who trained in their home countries and only begin adapting to a foreign 
environment upon job placement. As the latter becomes more common, systematic examinations are needed that elaborate the situation of international teachers who also learn to teach within international contexts.

\section{The Hong Kong context: Internalisation and Liberal Studies}

Beyond the NET scheme, internationalisation in education is not particularly new or novel in Hong Kong. Throughout its modern history-as part of the British Empire and then as a Special Administrative Region of China since 1997-Hong Kong education has been conceived as a kind of wok of international pluralism: "separate ingredients are rapidly and briefly stir-fried...their tastes rarely mix” (Sweeting, 1992). Early Hong Kong educational policymakers (British expatriates) bemoaned the unwieldy diversity of the society, given its dynamic population of British, Chinese, and Indian workers and their families (among others), many of whom would regularly travel between Hong Kong and home countries (Jackson, 2014b). The British took a relatively laissez-faire attitude toward schooling during most of the colonial period, enabling various private schools to operate fairly independently of the government, until massification of education in the 1960s and 1970s.

Today over 90 percent of schools are local in terms of curriculum and government oversight (using various government and private funding schemes), roughly mirroring the proportion of the population classified (by legal status) as local. In the international schools of Hong Kong (offering non-local curricula), the majority of teachers are international, including locally based “overseas” hires (Education Bureau, 2012). However, suitably trained international teacher education graduates can work in local schools, while local and international student teachers may also seek employment outside Hong Kong after finishing their degrees, as educational and teacher mobility increase. 
At the individual level, the motivations of those who aspire to work as international educators "determine what attracts individuals to teaching, how long they remain in their initial teacher education courses and subsequently the teaching profession, and the extent to which they engage with their courses and the profession” (Sinclair, 2008, p. 80). In Gu and Lai's (2012) research on motivations and commitment to teach among Mainland Chinese and local students in Hong Kong, they found that both groups of prospective teachers identified their reasons for entering into teaching as both intrinsic —interest in working with childrenand extrinsic-professional stability, long vacations, high initial salary, less competitive workplace, etc. Hong Kong-based students indicated more altruistic reasons, such as a love of children and the alignment of teaching with their moral values, than the Mainland Chinese students, though altruistic motivations have been found among Mainland Chinese beginning teachers who migrate for work within China (Jackson \& Adarlo, 2014).

Relatedly, Gu and Lai (2012) observed that Mainland Chinese students displayed less commitment to teaching than local counterparts in Hong Kong. Mainland Chinese students viewed teaching more often as a "non-elite profession," and expressed more doubt in their teaching capacity and ability to secure a position in a Hong Kong school upon graduation. A sense of inadequacy was seen to be aggravated by their common lack of Cantonese proficiency and/or familiarity with local culture, in comparison with local counterparts (Gu \& Lai, 2012). However, cultural differences in perceptions of the teaching profession can also play a role. South Korean youth and parents hold teaching as one of the most desirable professions, particularly for women (Song, Jang, Kim, Kim, Yun \& Park, 2014), although student teachers' motivations may also be impacted by an international teacher education context and/or international teaching context, and its challenges.

While Gu and Lai focused (2012) on student teachers in English education for their research, Liberal Studies is also a major part of the curriculum where international teachers 
could be successful in Hong Kong. Liberal Studies (LS) became a core subject in Hong Kong senior secondary education in 2009, alongside English, Chinese, and math. The medium of instruction and examination for LS can be English or Cantonese. LS is interdisciplinary, incorporating social studies and science knowledge, with modules including "Personal Development and Interpersonal Relationships,” "Public Health,” "Energy Technology and the Environment," “Globalization,” “Hong Kong Today,” and “Modern China.” Liberal Studies has multicultural and international educational aims, with goals including to help each student "to be an informed and responsible citizen with a sense of global and national identity," and "respect pluralism of cultures and views, and be a critical, reflective and independent thinker" (CDC, 2007/2014, p. 3). It aims in part to cultivate a globalised sense of identity in students growing up in an internationalised society.

However, the topics emphasised in the social domain in LS are often highly localised and framed by student's background knowledge and experience, which might be quite limited from a global view. "Hong Kong Today" deals with "quality of life in Hong Kong, rights and responsibilities with respect to the rule of law, socio-political participation, and the identities of Hong Kong residents"; "Modern China” focuses on "China's domestic policies and foreign relations, as well as its cultural developments” (CDC, 2007/2014, p. 25; p. 33). The subject's overall treatment of cultural diversity within and beyond Hong Kong, in these modules and in "Globalization," has also been found inadequate for achieving its multicultural/intercultural goals, with unbalanced, often prejudicial coverage of local and international minority communities, and pro-Western and pro-Chinese biases observed in commonly used curricular resources (Jackson, 2015). With such emphasis on localised topics that require teachers to have substantial knowledge about Hong Kong and China, additional training may be necessary for non-local prospective LS teachers to reach effective levels of "glocal” understanding. 
Liberal Studies teacher education became a degree programme offering in Hong Kong universities in 2009, the same year it became mandatory in local schools, with coursework and practicum requirements. As we researchers are an American university instructor (Jackson), and a South Korean former teacher education student (Han, now a teacher in Hong Kong), both recently arriving in Hong Kong, we both experienced instances where our identities as non-locals have negatively impacted our professional authority in relation to Liberal Studies undergraduate teacher education. As international professionals participating in teacher education for a partly local/partly "glocal” curriculum, we felt parallel pressures to learn local issues while teaching in a culturally foreign environment. And we faced fears that our students and peers (Jackson in university teacher education, and Han in local schools) would know more about the curriculum than we did-at least regarding local themes and perspectives. On the other hand, unlike traditional academic subjects, the curriculum's unique local perspective makes it in some ways less relevant to educators from outside of Hong Kong. Thus, we were relatively unprepared for Liberal Studies teacher education, and our continued development for Liberal Studies could be of limited utility outside of Hong Kong, in our respective home countries.

However as the new curriculum also represents a major effort toward internationalisation (and multiculturalism) of the Hong Kong curriculum, we as educators also experienced a sense that our foreign identities, backgrounds, and experiences could be advantageous at a different level, for enabling us to provide fresh perspectives on local and global issues in alignment with the curriculum's aim of empowering students to understand diverse views and perspectives worldwide. Thus, as one case of educational "glocalisation,” wherein a new "glocal” (global focus, from a local perspective) curriculum is implemented within an internationalising education setting, we sought to more systematically understand 
international students' motivations, experiences, and challenges in this context, elaborating one case of international students learning to be local/“glocal”-subject teachers today.

\section{Methods}

Our study aimed to examine the perceptions of South Korean Liberal Studies teacher education students, which represents the second-largest group of non-local students in the university’s teacher education programme (after students from Mainland China). Our research questions were: (1) What are the motivations for South Korean international students to apply and enrol in a programme in Hong Kong Liberal Studies teacher education? and (2) What are their experiences and challenges related to their international status and background (a) within the Liberal Studies teacher education programme and (b) in potentially becoming Liberal Studies teachers? Our research used a qualitative approach with in-depth case studies and semi-structured interviews to explore participants' perspectives and recollections of their experiences. This approach was suitable as the number of possible subjects was small, and we wished to understand participants’ views of their experiences in-depth.

\section{IV.a Participants}

The interviewing researcher's (Han’s) equivalent status as a South Korean LS student at the time of data collection assisted with recruiting and establishing a trusting and constructive relationship with participants. The first participants were found through the researcher's (Han’s) social networks within the South Korean university student and teacher education communities, before using a networking group online to approach the remaining participants. Out of eight South Korean Liberal Studies teacher education students enrolled in the institution at the time of the study, six students were recruited. (Apart from the student researcher herself, the remaining one potential participant was on leave from study during the time of the research). 2 of the participants were in their first year of study, 2 were in their second year, and 1 each was in years 3 and 4 of the programme. All participants entered the 
university through international admissions schemes. They had studied previously in international secondary schools in South Korea, the United States, or Mainland China, completing either the Advancement Placement (AP) programme, or the International Baccalaureate (IB) programme (see Table 1).

\begin{tabular}{l|l|l|l|l|l}
\hline $\begin{array}{l}\text { Name } \\
\text { (pseudonym) }\end{array}$ & Gender & $\begin{array}{l}\text { Native } \\
\text { language }\end{array}$ & Study year & $\begin{array}{l}\text { Secondary } \\
\text { schooling }\end{array}$ & $\begin{array}{l}\text { Secondary } \\
\text { curriculum }\end{array}$ \\
\hline Cindy & Female & Korean & 1 & South Korea & AP \\
Janice & Female & Korean & 1 & United States & IB \\
Teresa & Female & Korean & 2 & South Korea & AP \\
Mary & Female & Korean & 2 & China & AP \\
Lisa & Female & Korean & 3 & United States & AP \\
Karen & Female & Korean & 4 & South Korea & AP \\
\hline
\end{tabular}

Table 1. List of participants in the order of study year.

Notably, neither AP nor IB curricula provide anything equivalent to LS, though IB shares some philosophical aims with LS, particularly in a humanities subject called "Theory of Knowledge” (as shared by a participant). As revealed in the interviews, none of the participants had been exposed to the Hong Kong subject of Liberal Studies prior to their university admission, in contrast with local classmates. All participants were female, as are the vast majority of teacher education students today in Hong Kong.

\section{IV.b Methods and analysis}

Each participant was informed about the aims and purposes of the study during recruitment, and was asked for their informed consent before data collection, in line with institutional ethics requirements for gathering student data for research purposes. Research purposes, interview procedures, potential risks and benefits, and processes for ensuring confidentiality and storing data were explained in consent forms. A few minutes in the beginning of interviews were devoted to further explaining study aims and methods. Each interview lasted about one hour and took place in a reserved discussion room in the university's library. An interview guide was used which was shared with participants in 
advance, prepared in Korean and English. Questions ranged from education background and entry motivation, to learning progress and experience, benefits and challenges, and future professional hopes and prospects (see Appendix A). However, the guide was not strictly followed, and participants were encouraged to freely share.

Participants had the choice between English and Korean for conducting the interview, and all participants chose Korean, their (and the interviewer's) mother-tongue language. The interviews were conducted in the second semester of the school year (mid-2015), to include teaching practicum experience particularly of the first and second-year student participants, as research has found that teaching practice is often held as more enjoyable and meaningful than coursework for teacher education students, and as more closely related to students' motivations for entering the teaching field (Commonwealth of Australia, 2007; Sinclair, 2008). Audio-recordings were transcribed in Korean, and then analysed for common themes across responses and in relation to previous research. Responses were grouped into answers to major thematic questions and translated into English by the interviewer/researcher.

While the use of primary language to conduct interviews ensures originality and unmediated responses that suit the purposes of qualitative research investigation participant perceptions, translation and interpretation may raise issues of validity (Temple \& Young, 2004). However, any process of attaining comprehension of another's views and perceptions requires "translation" of some sort, which may result in a change in perspective. Therefore, analysis was grounded by the transcripts. Data analysis was conducted dialogically by the researchers. First, parallel analysis of transcribed findings in English was conducted by both parties independently. Any findings that were not confirmed by the transcripts through this process were further examined and analysed in relation to trustworthiness and generalizability over the sample. The findings given here represent those generalisations over the sample and analyses that met the approval of both researchers via independently 
conducted analyses of the data. Findings are framed in the following section according to the motivations, experiences, and challenges of the participants in studying Liberal Studies teacher education and considering becoming Liberal Studies teachers in Hong Kong.

\section{Findings}

\section{V.a Motivations (versus realities) of Liberal Studies}

With regard to initial motivations, four out of the six participants identified past experience volunteer teaching as a major influence on their choice to study education. Most also expressed explicitly that they chose to study teacher education because they wished to become teachers, in Hong Kong or elsewhere after graduation (not necessarily in LS). The following are representative extracts from these participants:

"I did volunteer work in education. I've wanted to become a teacher or a social worker since I was in high school, and eventually I steered towards education. The biggest reason for this was because I used to volunteer at a special education school, and watching the students grow while learning was a very rewarding experience.” (Cindy)

"I have always wanted to become a teacher, so I gradually grew an interest in education. I love working with children, and I thought becoming a schoolteacher would be the perfect decision for my future...I did many volunteer hours in orpanages and kindergartens and was exposed to working with children; that is where my interest comes from.” (Teresa)

All participants expressed a positive impression of teaching as a profession, which some of them further connected to views of culture and gender:

"Coming from Korean culture, being a teacher is a great profession for a woman. It is commonly said that men prefer to marry a teacher out of all occupations in Korea.” (Janice)

"I always thought that if she had the right teaching, philosophy, and passion, being a teacher would be the best way for a woman to mature beautifully.” (Karen)

Participants also gave explanations that reflected their positive experiences of educators in their schooling:

"I have a good impression of the occupation because I had great teachers in my life." (Cindy) 
"When I first went to the States to study, I didn't speak English well, and that made me very timid. The teacher I met there was very approachable, she always talked to me first, and made sure I understood what we were learning in advance. She gave a lot of attention to me and told me it was okay to make mistakes. She was very encouraging, and so she is the reason why I have a good impression of teachers.” (Lisa)

They also mentioned economic aspects of the job, or other perceived benefits, particularly stability:

"It is extremely hard to find a job nowadays, and so people value stability of a profession very highly. That's the reason why it's getting harder to get into teacher's college in Korea. People think teaching is a very stable job.” (Janice)

Altruistic intentions were also emphasized by nearly all the participants:

"I love being around people, especially kids, and the idea of mentoring them fascinates me. It would be a truly rewarding experience to witness the growth of my students.” (Cindy)

"Teaching as a profession is great, because you get to be in a position to inspire others. If I can inspire just one person, I would still feel great.” (Mary)

However, despite strong interest in education and teaching, five out of six participants did not know anything about LS before enrolling in the LS teacher education programme. As they emphasized, none had studied LS as secondary students, though they did study international curricula (IB and AP). As student recruitment resources provided by the university do not explicitly elaborate on Liberal Studies as a particular school subject, independent research would have been necessary for them to understand the programme and subject, and the participants did not do such outside research. Instead, three of the participants indicated that they had conflated LS (the secondary curriculum) with educationoriented Liberal Arts (the larger, abstract tradition of a broad interdisciplinary education).

"During my entrance interview, a professor asked why there are so many Koreans applying for the programme. I think the reason is because most of them don't know LS is a subject taught in Hong Kong. They probably thought LS is a lot like Liberal Arts.” (Mary)

"I never knew about LS before coming...In the states, there is a tertiary institution called 'Liberal Arts College', so I thought LS would be something similar to Liberal Arts. I 
thought it could be about 'well-rounded education'. I had no idea LS was a core subject in Hong Kong curriculum.” (Teresa)

Consequently, the participants found the start of the programme overwhelming, upon discovering LS was a local curriculum and not Liberal Arts:

"I feel like studying LS as a student. I feel stressed for having to teach a subject that only exists in Hong Kong.” (Janice)

“The makeup of words 'Liberal Studies' is not at all unfamiliar, so I mistook it as Liberal Arts. So in my first year of study, I was devastated and felt out of place.” (Mary)

"I still remember in my first semester in year one, a professor gave us a paper to write down something we know about LS. I was perplexed because I didn’t know anything about it.” (Lisa)

These participants experienced much confusion in beginning their study due to a basic lack of understanding or familiarity with LS as a subject.

\section{V.b Experiences learning Liberal Studies: Good and bad}

Given their gap in understanding in relation to their motivations for enrolling in Liberal Studies teacher education, participants reported a sense of anxiety as they compared their starting point of learning to that of local students:

"It's hard for me as a foreigner with no prior experience in LS, to learn to teach such a local subject.” (Teresa)

“All of my local classmates have studied LS as a student, but I have not, and I think that's unfair. I think it’s hard to teach something that you have not learned as a student.” (Lisa) "I am not as experienced in LS as my peers, and this lowers my self-esteem and as a result, I don't feel confident enough...I become a passive learner.” (Cindy)

"I am worried about whether I can perform as well as my peers, considering the fact that I have never learned LS as a student.” (Janice)

The majority believed that insufficient exposure to LS or a similar subject in secondary school hindered their progress in learning the subject and how to teach it. The feeling of unfairness was most prevalent amongst participants who believed their secondary curriculum 
contrasted with LS: those participants who studied in the AP program during secondary education (5 out of the 6 participants).

"I studied the American curriculum, and it is very departmentalized. LS is very different from AP courses in the sense that it values interdisciplinary learning. It's hard for me to understand the concept, as I learned the American curriculum.” (Mary)

On the other hand, participants also commonly noted that a benefit of learning LS in their academic programme was the opportunity to explore different aspects of Hong Kong. Thus LS is viewed as a programme of study that "kills two birds with one stone," systematically developing valuable host country knowledge. Additionally, even though participants shared discontent regarding their lack of understanding of LS due to their foreign backgrounds, they positively regarded LS for its novelty. Hence a sense of ambivalence was ultimately reflected in their perspectives about their course of study and the subject of LS.

"LS has given me a fresh outlook on education due to its contrast to conventional rotelearning-oriented education...I still don't know much about the Hong Kong educational system, but one thing for sure that I like about LS is that it's different from Korean education.” (Teresa)

\section{V.c Challenges adapting: At university and in teaching practice}

Participants indicated facing many challenges in their educational experience, both within the university and in teaching practice. Many emphasized dissatisfaction and disappointment in relationships with local students and university faculty. They reported feeling avoided by local peers in pairing up for teaching practice and group work, due to their inability to speak Cantonese and relative lack of comprehension of Liberal Studies:

"I sense that local students in general do not want to pair up with international students. It's probably because we lack in understanding of the subject and so we would need help constantly. I feel as if local students consider us as burdens, and that makes it harder for me to approach them.” (Mary)

"Professors advised that international students pair up with local students, but...none of the local students wanted to pair up with international students.” (Teresa) 
In elaborating such dissatisfaction, participants commonly expressed desire for more active and systematic support from faculty to international students. Instead, a passive approach to ensuring equal learning experiences was seen as inadequate by participants:

“The faculty didn’t provide much support in arranging workshops or seminars to address the problems faced specifically by international students. These problems could be things about unfamiliarity of the curriculum as well as the local school structure. We need more in-depth workshops tailored to international students.” (Karen)

However, this participant also emphasised that to achieve cooperation, effort from both sides—students and the faculty—is indispensable:

"But the professors are willing to help when approached. It's something that we need to work together on; no one side is to be blamed for non-local students' difficulties in adapting to the curriculum.” (Karen)

Participants unanimously identified a language barrier as a major factor that limited their teacher education. According to their report, problems related to language difference were among the most prevalent and severe of cross-cultural challenges they faced, within the university and in school teaching experience. A common example given was the normal usage of Cantonese during in-class small group discussions and while working on group assignments in university, in nonalignment with the institution's English medium of instruction policy. Despite attempts to be proactive in regard to their learning needs, participants often felt excluded, stigmatised, and disengaged by language differences.

"It was most difficult to handle my group mates working on an assignment together for my entire first semester of university. They spoke so much in Cantonese that I felt isolated, and it disrupted my learning. Even during lecture when we are given a task to discuss as groups, peers always speak in Cantonese, so that makes it hard for me to participate.” (Cindy)

“There definitely is a language barrier in majoring in this programme. This is a setback in my learning because my classmates speak in Cantonese a lot of the time. I have nearly given up on this issue. I tried hard to get along, and I even confronted them about it, but nothing has changed.” (Teresa) 
"Many peers use Cantonese when we are doing group assignments, and that made it extra hard for me to join and follow throughout the process. I was very stressed out.” (Lisa)

Most participants added that many professors also casually integrated Cantonese while delivering lectures, which, in the words of one participant, "sets the tone of the classroom where speaking Cantonese is acceptable” (Mary).

"It's hard being a foreigner here, because there is always a language barrier. Some professors use Cantonese here and there, in their PowerPoint and lecture speech.” (Cindy) "Such a small act [of instructors lecturing in Cantonese] makes me feel left out and excluded. Many peers speaking in Cantonese during group assignment is also a big problem that disrupts the flow of my learning.” (Mary)

One participant reported an experience she had in a mandatory programme-organised field trip. Cantonese was mostly used throughout the trip, and she had to ask for classmates to translate for her on a voluntary basis. The participant felt that her learning seemed to obstruct or impede her local peers’ learning, due to her need for translation.

In school teaching practice settings, the participants experienced similar challenges. One noted that her experiences and understandings as a non-local could ideally bring "a fresh perspective” (Karen) to local counterparts, and vice versa. She identified such a mutual benefit from cultural difference as consistent with the core values of LS, including respect for multiculturalism and pluralism in society. However other participants expressed concern that Hong Kong educators preferred that LS classes be taught in Cantonese, due to students' convenience:

"During a school visit in a LS classroom, a teacher would ask a question in English and the students would respond back in Cantonese. Such problems are practical problems, and add to my doubt in whether I can teach LS.” (Cindy)

"I would have thought about becoming a LS teacher as a lifelong career, but for now the language barrier is the biggest hurdle. It's going to be so difficult to communicate with students as well as the entire school if I don’t speak [Cantonese].” (Teresa)

\section{V.d Becoming a Liberal Studies teacher}


All participants expressed concern about their employment prospects after graduation. One reason for their apprehension was that LS is taught only in Hong Kong and is not entirely transferrable to other societies, while the programme is also oriented toward teaching in Hong Kong:

"I feel like the programme is focused in training teachers to only teach students in Hong Kong. It's a lot of pressure to know that we will be teaching students towards taking the national exam. I think things that we learn now will be difficult to apply within other countries' curriculum. I don't see myself as a future LS teacher, so I have a lot of concern about whether the things I learn now will help me in my future.” (Janice)

"I am also worried whether I can teach LS well to local students in the future. I have heard that we will be teaching about local culture as well, and I am not so sure how well I can manage doing that.” (Janice)

An additional factor related to adapting to the local school environment while being identified as an international teacher:

"I got the general feeling that the students wouldn't trust me as a teacher due to my nationality...I don’t feel confident or well prepared to teach LS.” (Lisa)

These participants reveal anxiety to teach based on insufficient knowledge and cultural understanding of Hong Kong, while most also expressed concerns that school stakeholders (parents, administrators, etc.) may not see an international LS teacher favourably, negatively affecting their employment options.

When asked specifically if they believed they could become LS teachers upon graduation, responses were half and half. Language was seen as the tallest hurdle, as well as non-local identity and comparably lesser ability to prepare localised teaching materials (such as using writings from local news, which are often in Cantonese only). While some noted the potential for their diverse cultural backgrounds to benefit students, particularly as LS classes and examinations can be conducted in English (though this is less common), due to their 
perceptions of the contemporary context of Hong Kong education, none expressed feeling committed to becoming LS teachers.

“According to one professor...students' level of communication in English, through projects and essays, will not be sufficient...That is the reason why there are many LS classes even in [English medium-of-instruction] schools that are conducted in Cantonese. [English medium] schools are less than $50 \%$ of the pool of local schools in Hong Kong. There are even less LS classes solely conducted in English. So in conclusion, it is better for us international students to target international schools. (Karen)

Five out of the six participants expressed a preference to teach at an international school (where Liberal Studies is not taught) upon graduation, as they believed that adapting to teach at international schools would be easier than at local schools, given their previous educational background and the Hong Kong contemporary context.

\section{Discussion}

This research adds to theoretical and practical knowledge about the emerging topic of internationalisation in education, and particularly teacher education, in some different ways. First, our findings elaborate a more nuanced picture of the motivations and commitments of international student teachers in Hong Kong and elsewhere, in relation to past research (Gu \& Lai, 2012; Sinclair, 2008). As discussed previously, Hong Kong local students are likely to give altruistic rationales for entering teacher education programmes and the teaching profession in comparison with Mainland Chinese students in Hong Kong, apparently due in part to differing cultural attitudes toward the teaching profession (Gu \& Lai, 2012). South Korean teacher education students likewise give altruistic reasons that additionally related, as some of the participants expliclty saw it, to their cultural background. These findings bolster past research on South Koreans' positive perceptions of the teaching field, and particularly of women's role within it (Song et al., 2014). 
South Korean LS students studied teacher education in Hong Kong with a distinct and strong commitment to pursuing teaching as a profession after university study, viewing teaching as intrinsically and instrumentally valuable within an international context. Interestingly, that they were entering into a (potentially unfamiliar) international educational environment did not seem to give them pause, as internationalisation was not entirely new for these participants, who studied overseas and/or used an international curriculum at the secondary level. They enrolled in a teacher education programme as international students to become teachers and explore the profession, unconcerned with the particular international aspects, good or bad, of their study or future career. These findings reflect that internationalisation may not be a particularly distinctive part of the appeal of an undergraduate programme from the perspective of international education students, but may rather be seen to be a more neutral feature, particularly among strong (successful) programme applicants, who are already internationally oriented.

This study also highlights the impact of different approaches to internationalisation of higher education upon international teacher education students. As discussed previously, internationalisation of education can be framed in ways that benefit different parties unequally. On the face of it, internationalisation reflects student curiosity for broader fields of knowledge. Educationalist views (and to a less extent, idealistic and even instrumentalist views) of internationalisation thus emphasize its benefits particularly for students (Burchill, 2009; Otten, 2003; Wanner, 2015). Such rationales may have been implicit motivators at a general level among participants, as they expressed seeking out Liberal Arts education as a reason for applying to the LS programme. Yet instrumentalist rationales for internationalisation also facilitate benefits of internationalisation to universities (Altbach \& Knight, 2007; Scott, 2006; Stier, 2004) from an economic or marketing perspective. In such cases the needs of diverse students may not be focused on, and academic standardization may 
lead to a neglect of their backgrounds, experiences, and cultures (Ashcroft, Griffiths \& Tiffin, 1995).

One might imagine that such challenges would not be so severe in this case as in some others, as Hong Kong and South Korea are relatively similar in culture and education from a global perspective, and given Hong Kong's historically international and cosmopolitan professional and educational culture. Nonetheless, because the participants in our study were interested in becoming international schoolteachers, they found educational barriers in their programmes and practicum experiences related to their international status disappointing and frustrating, particularly as their professional and learning needs seemed neglected in relation to those of local students. Building upon past research, our findings demonstrate that although participants entered their teacher education programmes with idealist, and partly instrumental, motives in mind (hoping to become schoolteachers), from the university's perspective academicentrism is observable, as little was done to prepare these particular students to understand the subject at the heart of their programme of study in advance or during its course, even though South Korean students would inevitably have low levels of LS knowledge.

The negative impact of such academicentrism (Stier, 2004) on students is vividly portrayed in the participants' expressions of feelings of inadequacy during their programme, in relation to their academic studies, teaching practice, and in building professional relationships. Though Liberal Studies is a glocal curriculum with an outward-looking face, learning LS is more complex for non-local and international students, as they have yet to learn the subject as they must learn how to teach it, simultaneously. Such double-learning processes were seen as demanding by participants. Although the participants wished to pair with more culturally knowledgeable classmates for teaching and learning tasks in order to "catch up,” an unequal understanding of LS seemed to create tension between local and non- 
local students. Participants thus identified their foreign curriculum background as a factor that hindered their progress and sense of belonging. In relation, students developed little motivation to become Liberal Studies teachers in Hong Kong, due to a sense of unavoidable exclusion, although they still saw teaching as admirable as they progressed.

The case thus provides evidence against internationalisation that is instrumentalist in nature from the perspective of international students. Despite a university and society's commitment to internationalisation of education, without focusing on the experiences and needs of international students, internationalising programmes may disproportionately enhance education in the interests of the university or local students. Inaction of faculty to ensure equal learning experiences of international students is a commonly identified shortcoming in the wider literature on internationalisation in higher education (Montgomery, 2010). Particularly when internationalisation occurs which is fuelled by economic incentives, there is a danger of cultural homogeneity at the structural level facilitating an academicentric learning atmosphere. Such uniformity is contradictory to educationalist calls for internationalisation that promotes pluralism in global society.

The expressed needs of the participants in this study point to contributions various stakeholders can make to better enhance their potential to develop and retain skilled, competent, and motivated international student teachers and teachers for Hong Kong Liberal Studies. As the study's findings echo some from previous investigations of the experiences of Mainland Chinese student teachers in Hong Kong, other international teacher education students from other nationalities may also encounter similar issues in adapting to a foreign curriculum, with aims to ultimately teach it. Many tactics and possibilities to help such international teacher education students in Hong Kong are also potentially applicable to other settings where internationalisation of higher education is on the rise, as some degree of 
academicentrism may be inevitable within dynamic internationalising contexts (Altbach \& Knight, 2007).

First, as international student intakes grow, universities should address predictable difficulties faced by these students as they adapt to a different culture and environment. This case brings out the need to facilitate international students' greater preparation particularly vividly, as non-local LS student teachers, compared to education students in English or science, have no prior experience in LS. However, cultural differences in curriculum and pedagogy across countries can arguably create related challenges for many international students more generally, across teacher education programmes, and across the higher education curricula. Given that higher education contexts (and particularly teacher education contexts) are often marked by a local majority, special seminars and workshops, as recommended by the participants, could examine challenges likely to be faced by international students, such as language barriers and more complex career prospects, to collaboratively devise constructive paths forward. Teacher educators should also demonstrate awareness that learning outcomes of non-local students may differ due to their educational backgrounds and lack of previous knowledge of local subjects. As LS is a Hong Kong-local subject, systematic guidance for non-local students is necessary to provide more equal opportunities, if faculty admit international students to programmes in good faith.

Finally, as mediators of discussions and role models in multicultural and international education, teacher educators should critically assess the impact of the usage of local languages during discussions. In Hong Kong many local university students are more comfortable expressing ideas in Cantonese than in English; in this context mandatory English-only classroom environments may be less effective for local students, as English can also be seen as a globalist imposition on the local setting. Nonetheless, considering this issue systematically as it presents itself can ensure more effective and equal learning opportunities 
and help establish a more welcoming atmosphere. Furthermore, in modelling international or multicultural educational aims, it is important for teacher educators to demonstrate and encourage respect for pluralism, working to eliminate barriers between students related to culture or language. They can provide space for students to develop open-minded perspectives toward each other through events aimed at their integration. Such possible interventions may be beneficial in a variety of higher education contexts, and their further examination can provide avenues for future research in this area.

\section{Conclusion}

This study has explored the experiences of South Korean LS teacher education students in a university in Hong Kong. In line with theoretical and empirical research on the experiences of international students and international student teachers in Hong Kong, this study gives a deeper look into the experiences of the second largest group of international students in Hong Kong teacher education, South Koreans, exploring their motivations, experiences, and challenges in studying to be Liberal Studies teachers. This study indicates that due to factors such as language barriers, foreign curriculum backgrounds, and lack of knowledge of Hong Kong in comparison with local counterparts, there is a sense of dissatisfaction with LS teacher education among South Korean students. Participants struggled in university, extracurricular, and teacher practice environments, due to their international status and particularly when Cantonese was used. Such inequality in language and base understanding demotivates non-local students in their studies and in becoming LS teachers, who could ideally help enhance the deeper realization of Hong Kong's identity as an international, multicultural society.

In light of Hong Kong's interests in developing glocal curriculum for an internationalised society, more deliberate efforts to foster positive motivation in non-local 
pre-service teachers can nurture more significant progress in international students' understanding of the subject and ability to teach it, consequently raising the possibility for retention and development of international LS teachers. Such efforts include addressing linguistic exclusion and devoting additional resources to help international students understand the local curriculum and prepare themselves for professional development, as international teachers may bring different strengths to schools than their local counterparts, as LS teachers.

More generally, this study confirms that academicentrism can be a felt experience of student teachers in international higher education in Hong Kong as elsewhere. If challenges related to difference overwhelm international student teachers, the message may be unwittingly put forward, both to international and local students, that the value of internationalisation of higher education is associated more with marketing and economic benefits than with learning from difference, for the enhancement of society for all of its members. Facing these challenges constructively is essential for higher educators who wish for a productive engagement of the international, and particularly international students, in their programmes. As models of constructive internationalisation, which is not only instrumentalist but also idealist and educationalist in perspective, faculty can make a positive impact on local and international students by demonstrating appreciation for the benefits of diversity, and actively embracing it in teaching and learning to enhance society as a whole. 


\section{References}

Altbach, P. G., \& Knight, J. (2007). The internationalization of higher education: Motivations and realities. Journal of Studies in International Education, 11, 290-305.

Aschcroft, B., Griffiths, G., \& Tiffin, H. (Eds.) (1995). The post-colonial studies reader. London: Routledge.

Besley, T. (2012). Narratives of intercultural and international education: Aspirational values and economic imperatives. In T. Besley \& M. A. Peters (Eds.), Interculturalism: Education and dialogue (pp. 87-112). New York: Peter Lang.

Burchill, B. (2009). Liberalism. In S. Burchill, A. Linklater, R. Devetak, J. Donnelly, T. Nardin, M. Paterson, C. Reus-Smit, \& J. True (Eds.), Theories of international relations. New York: Palgrave-Macmillan.

Carless, D., \& Walker, E. (2006). Effective team teaching between local and native-speaking English teachers. Language and Education, 20, 463-477.

Choi, Y. (2001). Suggestions for the re-organisation of English teaching program by native speakers in Korea. English Teaching, 56, 101-122.

Commonwealth of Australia. (2007). Top of the class: Report of the inquiry into teacher education. Canberra: Commonwealth of Australia.

Crystal, D. (1997). English as a global language. Cambridge: Cambridge University Press.

Curriculum Development Council (CDC). (2007/2014). Liberal Studies: Curriculum and assessment guide (secondary 4-6). Hong Kong: Education Bureau.

Education Bureau. (2012). Prospectus of the schools operated by the English Schools Foundation and international schools in Hong Kong. Hong Kong: Education Bureau.

Forrester, V., \& Lok, B. (2008). Native English teachers in Hong Kong: Building Communities of Practice? Asian Social Science, 4(5), 3-11.

Garten, B. (2000). Recruitment of teachers for international education. In M. Hayden \& J. Thompson (Eds.), International schools and international education: Improving teaching, management and quality (pp. 85-95). London: Kogan.

Giddens, A. (1990). The consequences of modernity. Cambridge: Polity Press.

Graddol, D. (1997). The future of English. London: British Council.

Gu, M. (2013). Cultural identity in teaching across borders: Mainland Chinese pre-service teachers in Hong Kong. Asia Pacific Journal of Education, 33, 407-423.

Gu, M., \& Lai, C. (2012). Motivation and commitment: Pre-service teachers with different historical backgrounds at a teacher education institute in Hong Kong. Teacher Education Quarterly, 39(3), 45-61. 
Ilieva, R., Beck, K., \& Waterstone, B. (2014). Towards sustainable internationalisation of higher education. Higher Education, 68, 875-889.

Jackson, L. (2016). Globalization and education. In G. Noblit (Ed.), Oxford research encyclopaedia of education (in press). Oxford: Oxford University Press.

Jackson, L., \& Adarlo, G. (2016). “Soft Power”, selfishness, or altruism? Motivations and satisfaction of US-based international volunteers. International Journal of Diversity in Education (in press).

Jackson, L. (2015). Religion in Hong Kong education: Representation in Liberal Studies textbooks. Asian Anthropology, 14(1), 43-46.

Jackson, L. (2014a). Under construction: The development of multicultural curriculum in Hong Kong and Taiwan. The Asia-Pacific Education Researcher, 23, 885-893.

Jackson, L. (2014b). Who belongs in what Hong Kong? Citizenship education in the special administrative region. In J. E. Petrovic \& A. M. Kuntz (Eds.), Citizenship education around the world: Local contexts and global possibilities (pp. 22-42). London: Routledge.

Jackson, L., \& Adarlo, G. (2014). Bridging cultures through unpaid labor: U.S. volunteer teachers' experiences in China’s Yunnan Province. Voluntas. Advance online publication.

Krucken, G., \& Meier, F. (2006). Turning the university into an organizational actor. In G. Drori, J. Meyer, \& H. Hwang (Eds.), Globalization and organization: World society and organizational change (pp. 241-257). Oxford: Oxford University Press.

McNamara, O., Lewis, S., \& Howson, J. (2005). The recruitment of overseas trained teachers. London: National Association of Schoolmasters.

Montgomery, C. (2010). Understanding the international student experience. New York: Palgrave Macmillan.

Otten, M. (2003). Intercultural learning and diversity in higher education. Journal of Studies in International Education, 7(1), 12-26.

Reid, C., Collins, J., \& Singh, M. (2014). Global teachers, Australian perspectives: Goodbye Mr Chips, hello Ms Banerjee. London: Springer.

Ritzer, G. (1993). The McDonaldization of society. Boston: Pine Forge Press.

Rizvi, F., \& Lingard, B. (2010). Globalizing educational policy. London: Routledge.

Scott, J. C. (2006). The mission of the university: Medieval to postmodern transformations. Journal of Higher Education, 77(1), 1-39. 
Sinclair, C. (2008). Initial and changing student teacher motivation and commitment to teaching. Asia-Pacific Journal of Teacher Education, 36(2), 79-104.

Song, C., Jang, H., Kim, N., Kim, M., Yun, S., \& Park, B. (2014). Research on the actual condition of career education in schools. Retrieved from: http://www.krivet.re.kr/ku/zi/prg_kuZ_prA.jsp?dv=A\&gn=E1|E120150054|4

Stier, J. (2004). Taking a critical stance toward internationalization ideologies in higher education: Idealism, instrumentalism and educationalism. Globalisation, Societies and Education, 2(1), 1-28.

Sweeting, A. (1992). Hong Kong education within historical processes. In G. A. Postiglione (Ed.), Education and society in Hong Kong: Toward one country and two systems. Hong Kong: Hong Kong University Press.

Temple, B., \& Young, A. (2004). Qualitative research and translation dilemmas. Qualitative Research, 4, 161-178.

Von Kirchenheim, C., \& Richardson, W. (2005). Teachers and their international relocation: The effect of self-efficacy and flexibility on adjustment and outcome variables. International Education Journal, 6, 407-416.

Wang, L. Y. (2013). Non-native EFL teacher trainees' attitude towards the recruitment of NESTs and teacher collaboration in language classrooms. Journal of Language Teaching and Research, 4(1), 12-20.

Wang, L. Y., \& Lin, T. B. (2013). The representation of professionalism in native Englishspeaking teachers recruitment policies: A comparative study of Hong Kong, Japan, Korea and Taiwan. English Teaching: Practice and Critique, 12(3), 5-22.

Wanner, R. E. (2015). UNESCO's origins, achievements, problems and promise: An inside/outside perspective from the US. Hong Kong: Comparative Education Research Centre/University of Hong Kong. 


\section{Appendix A: Interview Protocol (adapted for anonymity)}

\section{Interview Questions}

International students' teacher training: South Korean Liberal Studies students in Hong Kong

The interview is semi-structured and is to last approximately 45 minutes minimum. Although an interview guide is used, participants are encouraged to expand upon their experiences whenever possible, in order to enhance the researcher's understanding of their perceptions.

1. Please share about your educational background.

a. Where did you study before coming to Hong Kong?

b. How many years did you stay in each school or country?

2. Why did you decide to attend an education programme in Hong Kong?

a. What are the merits of attending this Liberal Studies programme?

b. How is it for you to learn about education in a foreign country?

3. Why did you choose to study Liberal Studies in particular?

4. What do you think about Liberal Studies as a subject?

a. What are some merits of being a Liberal Studies teacher in your opinion?

b. Has your understanding of Liberal Studies changed along your years of study?

5. What do you think about teaching as a profession?

a. What are your motivations for becoming a teacher?

b. What do you think about teaching as a lifelong career?

6. Can you share about your future plans? Do you want to become a teacher?

7. If you were to become a teacher, where would you want to pursue it?

8. How would you describe your experience in teaching practicum in Hong Kong? (When, where, what did you teach, etc.)

a. What are differences and similarities between South Korean and Hong Kong education (such as teaching methods)?

9. What are the pros and cons of receiving teacher training in Hong Kong/at this university?

10. Have you experienced any cultural conflict/shock as a foreigner during your teacher training (including teaching practicum) in Hong Kong?

11. Do you think a foreigner can teach Liberal Studies as a full-time school teacher? 